\title{
A cidade e o shopping: considerações sobre a relação urbana envolvendo a presença de shoppings centers e o caso da cidade de Blumenau-SC durante a década de 1990
}

The city and the mall: considerations in urban relationship involving the presence of malls and the case of the city of Blumenau-SC during the 1990s

André Procópio Gomes ${ }^{*}$

\begin{abstract}
Resumo
Apesar dos anos 1980 serem apontados como o primeiro grande momento em que shoppings centers são construídos no Brasil, é durante os anos 1990 que esse tipo de empreendimento urbano se espalha pelo território nacional para além dos limites das capitais. O Shopping Neumarkt, inaugurado em 1993 na cidade de Blumenau, Santa Catarina, entra nesse movimento de expansão em direção às cidades de porte médio no interior. Por meio do uso de periódicos e entrevistas orais, dois acontecimentos-chave são abordados: a inauguração e consolidação do Shopping Neumarkt e a reurbanização da rua XV de novembro, compreendendo todo o período da década de 1990. Pelo fato de essa reurbanização ser usualmente apontada como uma maneira de transformar a rua XV de novembro num shopping a céu aberto, foi desenvolvida uma relação entre a construção do Shopping Neumarkt e a cidade de Blumenau. O objetivo da pesquisa está em compreender uma nova forma de relacionamento da cidade. Mais do que destruir a urbanidade clássica, os shoppings produziram uma nova forma de conceber a urbanidade.
\end{abstract}

Palavras-chave: Shopping; História urbana; Urbanismo; Blumenau.

\begin{abstract}
The 1980s are target as the first big wave in mall construction in Brazil, besides it is in the 1990s that this kind of urban enterprise become a national reality beyond the main cities. The Neumarkt Mall opened in 1993 in Blumenau, state of Santa Catarina, and it is inside the movement toward the medium cities in the countryside. Through the use of newspaper and oral interview, two key events are addressed. The inauguration and consolidation of Neumarkt mall and the redevelopment of XV de novembro street, covering the entire period of the 1990s. As this redevelopment is usually identified as a way to transform the XV de novembro street into a open sky mall, a relation between the Neumarkt construction and the city of Blumenau is developed. The research goal is understand a new way of relationship with the city. More then destroy the classical urban model, the malls produced a new way to conceive the urbanity.
\end{abstract}

Keywords: Mall; Urban History; Urbanism; Blumenau.

\section{Introdução}

Os shoppings centers são um tipo de empreendimento que toma sua forma atual nos EUA na década de 1960. O Brasil conta com seu primeiro empreendimento dessa natureza em 1966 com a construção do Iguatemi na cidade de São Paulo. Apesar desses

\footnotetext{
* Doutorando em História pela Universidade do Estado de Santa Catarina (UDESC). Mestre em História pela Universidade do Estado de Santa Catarina (UDESC).
}

Recebido em outubro de 2016 | Aprovado em junho de 2017. 
primeiros indícios na década de 1960, sua grande consolidação é entendida de forma consensual como ocorrendo na década de 1980, período em que o Brasil apresentou uma grande quantidade de shoppings sendo construídos (PINTAUDI, 1992). Tomando a Região Sul do Brasil como exemplo, percebemos que é na década de 1980 que as capitais dos três estados (Paraná, Santa Catarina, Rio Grande do Sul) construíram seus primeiros shoppings, respeitando a tendência entendida como nacional.

Apesar do eco de uma tendência nacional, o estado de Santa Catariana e, mais ainda, Blumenau, reservam suas particularidades. Por exemplo, Santa Catarina tem sua população urbana ultrapassando a rural na década de 1980, enquanto a tendência nacional aponta a década de 1960. Blumenau seria uma cidade de porte médio na região do Vale do Itajaí com seus 250 mil habitantes ao longo da década de 1990. Segundo dados estatísticos da Associação Brasileira de Shopping Centers (ABRASCE), atualmente a Região Sul conta com 16,9\% do total de shoppings, um número diminuto em relação aos $55 \%$ da região sudeste ${ }^{1}$. Entretanto, esse percentual configura o Sul como a segunda região do Brasil com maior concentração de shoppings centers. Desse mercado em Santa Catarina, o Grupo Almeida Júnior detém 60\% do market share, constituindo o maior grupo brasileiro de shoppings de olho no segmento regional ${ }^{2}$. O primeiro shopping do Grupo Almeida Júnior foi o Neumarkt.

Além de Blumenau, outras importantes cidades do interior dos estados do Sul tiveram shoppings inaugurados ao longo da década de 1990, configurando, assim, uma segunda onda. Nas capitais, tanto a inauguração de novos shoppings, como também reformas e expansões nos existentes não cessam. A novidade são as cidades do interior com shoppings sendo inaugurados. Assim, a década de 1990 é caracterizada pela construção dos shoppings centers para além dos limites das capitais, consolidando de fato a presença de shoppings no Brasil. É nesse movimento que Blumenau e o Shopping Neumarkt se inserem.

O artigo aqui apresentado é uma adaptação do terceiro capítulo de minha dissertação, cujo mote narrativo se desenvolveu em torno de dois acontecimentos chave, a inauguração do Shopping Neumarkt em 1993 e a reurbanização da rua XV de novembro no ano 2000. Para os que não estão familiarizados com Blumenau, essa

\footnotetext{
1 Dados retirados de: <http://www.portaldoshopping.com.br/site/monitoramento/numeros-regionais>. Acesso em: 28 jun. 2015. É interessante observar que apesar do número de shoppings ser maior na região sul, com 89 em comparação aos 76 estabelecimentos na região nordeste, a Área Bruta Locável (ABL) da região nordeste é maior com 2.274.676 frente os 1.905.963 de ABL do sul.

${ }^{2}$ Dados retirados de: 〈http://www.almeidajunior.com.br/pt-br/mercado/>. Acesso em: 17 jun. 2015.
} 
cidade apresentou ao longo do século XX não só uma produção industrial considerável, como também um comércio expressivo em torno da importante rua XV de novembro. É através da XV de novembro e arredores que Blumenau apresentou o melhor de seu comércio, não sendo raro a visita de pessoas de outras cidades do estado ou do país, em especial após a invenção de uma Blumenau germânica na década de 1970 (FLORES, 1997). Cabe advertir que há em torno de Blumenau uma forte identificação germânica como resultado desse processo turístico realizado durante os anos 1970. Essa invenção identitária buscou legitimidade no passado colonial da cidade, fundada em 1850 por imigrantes alemães. Para ver melhor essa questão identitária em torno da construção do Neumarkt, perceptível a partir do nome alemão desse shopping (na língua alemã $\mathrm{Neu}=$ novo, markt $=$ mercado), sugiro a íntegra do primeiro capítulo da dissertação que deu origem a este artigo (GOMES, 2016). O foco aqui está na relação urbana propriamente dita, partindo do fato de o Neumarkt se localizar na rua 7 de setembro, uma rua paralela à rua $\mathrm{XV}$ de novembro, a poucos metros do mais significativo comércio blumenauense. Ao perceber essa reurbanização da rua XV de novembro concluída no ano de 2000, uma relação entre a cidade e o shopping foi tecida.

Um dos principais objetivos da pesquisa era compreender essa relação para além da destruição do urbanismo mais clássico, em que se concebe a rua como o grande espaço da urbanidade. Não há como negar que os Shoppings Centers tiveram papel fundamental na morte das cidades, destruindo a relação mais clássica do urbano, dado sua ligação com uma proposta modernista de racionalizar o espaço em grandes conjuntos arquitetônicos de confinamento, questão pontuada na década de 1960 por Jane Jacobs (2000). Mesmo a contragosto, o que temos é a constituição de uma nova relação urbana, dado que as cidades ainda existem e sujeitos ainda habitam e frequentam esses espaços, porém não mais da mesma maneira.

As fontes da pesquisa são entrevistas orais e periódicos. O periódico utilizado de forma mais exaustiva é o Jornal de Santa Catarina (JSC). O trabalho esteve sob uma constante ressalva: evitar o lugar-comum de que as cidades brasileiras seriam péssimas por simples falta de planejamento. Discute-se constantemente a cidade e quase todo cidadão possui algo para dizer, sugerir e interpretar sua cidade, pois "a cidade é objeto de múltiplos discursos e olhares que não se hierarquizam, mas que se justapõe, compõem ou se contradizem, sem, por isso, serem uns mais verdadeiros ou importantes que os outros” (PESAVENTO, 1999, p. 9). Dessa forma, o periódico foi encarado em sua potência de observar a "difusão de novos hábitos, aspirações e valores, as demandas 
sociais, políticas e estéticas das diferentes camadas que circulam pelas cidades" (LUCA, 2006, p. 120). Mesmo que os periódicos tenham sua limitação ao serem fruto de uma seleção e edição, é possível compreender uma pauta e algo da discussão sobre a cidade.

Cinco pessoas com diferentes perfis foram entrevistadas, cabendo apresentá-las devido aos diferentes lugares de fala que cada uma delas ocupa e, com isso, nos ajudar a compreender sua narrativa. Cláudia Siebert, além de sua atuação como professora no curso de Arquiteta e Urbanismo da FURB, foi secretária do planejamento na gestão de Victor Sasse (PL) e atuou no Instituto de Pesquisa e Planejamento Urbano de Blumenau (IPPUB). Arno Buerger Filho era dono das lojas Casas Buerger e foi presidente da CDL - Câmara de Dirigentes Lojistas - no momento em que Décio Lima (PT) assumiu a prefeitura de Blumenau, constituindo-se numa importante figura nas articulações para a consolidação da reurbanização da rua XV de novembro. As Casas Buerger constituíam uma das tradicionais lojas de Blumenau que se instalaram no Shopping Neumarkt desde sua inauguração, bem como contavam com variado número de lojas na rua, inclusive fora de Blumenau. Por essa particularidade das Casas Buerger, foi entrevistado Irineu Falk, funcionário de longa data e ainda ativo na Cia do Homem, que desenvolveu sua atuação tanto na loja da rua XV de novembro quanto na loja no Neumarkt. José Geraldo Pfau é publicitário e articulou muitas das campanhas da CDL, inclusive foi apontado por Arno Buerger como uma das pessoas que lhe auxiliaram em inúmeras atividades, em especial a reurbanização da XV. Por fim, temos Lili que preferiu a adoção de pseudônimo $^{3}$ e em respeito a esse desejo não será informado mais nada a seu respeito.

\section{Construindo o mundo da via expressa}

O Shopping Neumarkt foi construído na região central da cidade de Blumenau. Ainda hoje, a região concentra boa parte do comércio e de serviços. Devido à geografia do Vale do Itajaí, com muitos morros, a ligação entre o norte e o sul da cidade de Blumenau deve ocorrer imperativamente pelas ruas do centro. A região central apresenta essa densidade devido ao primeiro plano diretor de 1977 que conduziu o crescimento da cidade através do adensamento do centro. Porém, em 1983 e 1984 Blumenau passou pelas suas duas últimas grandes enchentes, "e isso alterou completamente a relação da cidade [...] com o espaço urbano" ${ }^{\text {. }}$. Dessa forma, Blumenau

\footnotetext{
${ }^{3}$ Para todos entrevistados ficou em aberto a opção pela adoção de pseudônimo.

${ }^{4}$ Cláudia Siebert. Entrevistada por André Procópio Gomes. Blumenau, 21 out. 2015.
} 
passa por um movimento de fugir da enchente, seja em busca de terras mais altas ou verticalizando.

Com isso, entendemos a resposta institucional do plano diretor de 1989 ao direcionar o crescimento da cidade para a região Norte - uma região menos densa, mais alta e plana em relação ao centro. A região central expande seus limites durante a década de 1990, configurando os efeitos do macrozoneamento e sua "finalidade de orientar o desenvolvimento do Município, direcionando o crescimento para as áreas mais adequadas à urbanização", que, a partir do Plano Diretor de 1989, fica definido a Região Norte como a "área para onde se direcionará o crescimento da cidade a médio e longo prazo, com a correspondente expansão da rede de infraestrutura básica." (PREFEITURA MUNICIPAL DE BLUMENAU, 1989, p. 31).

Dessa forma, é anunciado pelo JSC que as "rodovias de acesso são as prioridades de toda região", não só devido às festas que estavam para ocorrer na cidade, como "o projeto é de importância econômica também do Estado, pois deverá auxiliar no escoamento da produção existente na região" (JSC, 25/01/1991, p. 13). Veremos que "segundo a Assessoria de Planejamento elas não deixam de ter uma importância regional por se tratarem de ligações viárias com outras cidades do Médio Vale com aspectos econômicos muito fortes" (JSC, 25/01/1991, p. 13). Essas vias de acesso constituem os anéis viários e a via-expressa. Dessas vias de acesso, apenas um dos anéis viários (foram planejados três) e a via expressa foram construídos ${ }^{5}$.

Com as propostas do Anel Viário, bem como o foco dado para a construção da Ponte do Tamarindo, projeto apresentado nas páginas do Jornal de Santa Catarina como estado "na gaveta há mais de 20 anos" e "de fundamental importância para a cidade, pois vai ligar duas vias de grande fluxo" (JSC, 13/07/1995, p. 3A), podemos perceber uma constituição viária da cidade visando à fluidez do trânsito por meio de vias expressas, largas, de mão única. Falamos de uma concepção comum nas cidades de maior porte no que se refere à adoção de anéis rodoviários. É vital deixar claro que a escala aqui é reduzida, e apesar de seus contornos menores, a concepção viária de Blumenau na década de 1990 é concebida a partir desse princípio. A cidade e o Vale cresceram e precisavam modificar sua estrutura viária. As circulações além de mais constantes também eram mais extensas do que outrora.

\footnotetext{
${ }^{5}$ Com uma ressalva para a questão da via expressa, que se divide em três etapas: $1^{a}$ a construção da ponte do Tamarindo e a conexão com o bairro da Fortaleza, $2^{\mathrm{a}}$ a conexão até a BR-470 e $3^{\mathrm{a}}$ a ligação com a região das Itoupavas (Zona Norte), sendo esta última etapa ainda inconclusa.
} 
Uma maneira de ilustrar isto está nas variadas reformulações do transporte público urbano de Blumenau. Mesmo havendo um sistema de transporte coletivo em Blumenau anterior aos anos 1990, é nessa década que o projeto de terminais de integração será executado. Posto como vantajoso devido a "economia, a segurança e o menor número de ônibus circulando pelo centro da cidade" (JSC 02/04/1995, p.1B).

Esses dois movimentos, visando maior circulação viária pela cidade de Blumenau pelas pautas de vias expressas e ônibus integrados por terminais, serão questões e obras constantes durante todo o período estudado. Ao longo da década de 1990, as principais ruas da cidade de Blumenau deixam de ter mão-dupla e passam a ter sentido único, é o caso da rua 7 de setembro (onde se localiza o Neumarkt), da rua XV de novembro e da Avenida Beira Rio. Essas três vias paralelas constituem as principais ruas do centro da cidade de Blumenau e, por isso, apresentam um elevado movimento. Mesmo não se tratando da construção de anéis viários ou autoestradas, a malha viária busca fluidez no famoso modelo da via expressa. A busca por essa fluidez e integração não está apenas relacionada ao famoso esquema de conectar cidades com a alta oferta de emprego com cidades-dormitório. A forma com que ocorreu a colonização do Vale do Itajaí, com vários núcleos de colonização, diminuíram a "macrocefalia urbana característica dos demais estados brasileiros, onde a predominância absoluta de uma única cidade na rede urbana do estado causa problemas urbanísticos traumáticos" (SIEBERT, 1996, p.15). Apesar de uma cidade como Blumenau se destacar, não é tão intenso o ato de deslocar-se para as cidades-polo pela manhã e regressar para cidades menores pela noite.

\section{A localização do shopping}

O Brasil produziu um fenômeno interessante nas suas cidades, pois os shoppings centers, salvo exceções, têm sua instalação longe da periferia, preferencialmente, em regiões centrais e já densamente utilizadas, ao contrário de seu padrão e recomendação urbanística de instalá-los nos limites urbanos. O Neumarkt é concebido dessa forma. Práticas não muito diferentes são adotadas com o Beira Mar Shopping na capital catarinense Florianópolis ou com o Atlântico Shopping em Balneário Camboriú-SC, todos construídos no mesmo período e em áreas densamente ocupadas.

O espaço no qual o Shopping Neumarkt foi construído é um antigo terreno preparado inicialmente para receber os festejos do centenário de Blumenau em 1950. 
Apesar da escassez de fontes sobre o local para além da festividade do centenário, ocorreram relatos sobre como ele era anteriormente ao Shopping Neumarkt ser construído. Cabe notar que não é difícil levantar um bom número de fotos no acervo do Arquivo Histórico de Blumenau envolvendo o centenário da cidade ou o supermercado Pfützenreuter, que ficava ao lado do referido terreno. As fotos do terreno em si são escassas, inexistentes. O que não é de se estranhar, pois tratava-se de um terreno baldio, ou melhor, sem nenhuma construção digna da eternização fotográfica. O terreno contudo não era sem uso, "se comenta que é um assunto que não foi bem definido até hoje, porque que ele [Jaimes de Almeida Júnior, fundador da Almeida Júnior, empresa que controla o Shopping Neumarkt] conseguiu se instalar num terreno basicamente comunitário, que era dos padres" $"$.

Temos, assim, margem para entendermos que apesar de seu ar baldio, esse terreno não era sem uso. Alguns relatos ocorreram em conversas despreocupadas, que ou não tinham possibilidade de registro, ou até mesmo eram finalizadas com uma negativa para entrevista. São relatos interessantes, quase fragmentados e relativamente variados $^{7}$. Alguns contam que ali ficava o Big Lanches do Feio, primeiro lugar a vender hambúrgueres na cidade de Blumenau, instalado primeiramente num trailer no terreno onde hoje se encontra o Neumarkt. Houve também relatos de uma lavação e de um pátio de venda de carros usados. Também foi comentado a realização de festas da Igreja Matriz católica, localizada a poucos metros do Neumarkt.

A discussão adentra o campo da memória, já que conversando com pessoas mais velhas, relatos e construções narrativas em torno do terreno onde hoje está o Shopping Neumarkt não são inexistentes. Apesar de um certo ar de incerteza, pautados pela distância temporal e ausência de versão oficial, essas narrativas não deixam de ser críveis. Por fim, independente da impossibilidade de fontes mais rígidas que os relatos despreocupados, usos e significados para aquele lugar desligados da presença de um shopping center são possíveis e existiram. Grosso modo, o subconsciente sedimenta diversas informações, registros, memórias, sem preocupar-se com uma organização préestabelecida com cronologia. Ainda assim, um entendimento de passado está presente devido a essa experimentação do tempo.

\footnotetext{
${ }^{6}$ José Geraldo Pfau. Entrevistado por André Procópio Gomes. Blumenau, 27 out. 2015.

${ }^{7}$ Cabe observar que esse tipo de episódio era comum no momento da identificação enquanto mestrando em História do Tempo Presente com tema de pesquisa em torno da relação de Blumenau com o Shopping Neumarkt. Quando essas pessoas eram instigadas a terem seu depoimento registrado, ocorriam negativas com justificativa na falta de tempo ou da frivolidade de seu depoimento.
} 
Podemos afirmar que a maior parte desses relatos é impreciso, divergem entre si e não tem a devida quantidade de registros (escritos, orais ou imagéticos). Contudo, não se pode descartar a transmissão de significados sobre esse local maiores que um terreno baldio. O fato de termos uma escassez de fontes objetivas como a metodologia histórica exige desde o século XIX, não nos impede de perceber a construção de uma narrativa oficial ligada ao shopping. Tal qual o terreno em que ele foi construído, o shopping terá uma relação e um significado com a cidade. Seu local nunca foi neutro, então por que sua instalação o seria?

O interessante de se trabalhar com todos os números do Jornal de Santa Catarina desde janeiro de 1991 até dezembro de 1999 está em perceber a dinâmica temporal através de continuidades e rupturas. De forma sucinta, temos a repetição que pode ser percebida temporalmente pelo horário do ônibus, que mais ou menos segue um cronograma independente das rupturas (sol, chuva, trânsito, humor, etc.). Essa é uma forma mais primitiva de entender o tempo, já que está ligado à natureza ${ }^{8}$. Em meses como dezembro, a pauta sobre o natal, ou em outubro a pauta sobre a Oktoberfest são constantes e esperadas todo ano nas páginas do Jornal de Santa Catarina. Porém, podemos perceber questões inesperadas, a exemplo da compra do Jornal de Santa Catarina pelo Grupo RBS, e a rápida mudança que ocorre no jornal desde seu layout até a composição dos temas, cadernos e sua edição de texto, sem necessariamente demitir colunistas já consolidados.

É a partir dessas colocações que, por volta do ano de 1997, a presença do Shopping Neumarkt, por meio dos até então intensos informeciais ${ }^{9}$, escasseia-se nas páginas do Jornal de Santa Catarina. Reportagens ligadas ao Shopping praticamente desaparecem. Até mesmo propagandas envolvendo as variadas promoções realizadas diminuem sua exposição. Não só em quantidade, muito intensas nos primeiros anos, mas até no tamanho, pois muitas vezes ocupavam uma página inteira e, a partir desse ano, começam a ocupar espaços cada vez menores. O Shopping deixa de aparecer de forma declarada, mas ele não desocupa as páginas do jornal por inteiro.

Uma reportagem tratando de calouros não blumenauenses na Universidade Regional de Blumenau (FURB) sob o título Uma vida nova na universidade, trata dos desafios enfrentados pelos calouros e das mudanças ocasionadas na cidade,

\footnotetext{
${ }^{8}$ Esta questão entre o tempo da natureza e o tempo histórico é baseada na discussão realizada em Reinhart Koselleck (2014, p.73-89), Estratos do tempo: estudos sobre história.

${ }^{9}$ Termo coloquial para nomear as propagandas em formato de matéria jornalística.
} 
notadamente no setor imobiliário. Para ilustrar essa questão, temos uma foto do interior do Shopping Neumarkt com a legenda "Público jovem: fatia que movimenta a economia local" (JSC, 02/03/1998, p.1B). A situação se repete meses mais tarde durante a notícia de uma das vitórias do Brasil na copa de 1998. No texto podemos ler que "os torcedores comemoraram bem ao estilo brasileiro" ao invadirem "as ruas de carro, a pé, de bicicleta", com "tudo regado a muito barulho e cerveja", somado ao som da axé music. O ocorrido se deu "em plena Rua XV de Novembro, no coração de Blumenau” (JSC, 17/06/1998, p.5B). Contudo, a foto para ilustrar tal reportagem era a da praça de alimentação do Neumarkt cheia de torcedores eufóricos.

Quando observamos notícias do comércio em Blumenau, seja nas compras de Natal (JSC, 8/11/1998, p.4; 09/11/1998, p.4A) ou no dia dos namorados (JSC, 15/06/1991, p.8A), as fotos que ilustram a reportagem novamente são do interior do Shopping Neumarkt. O mesmo se passa quando tratam dos sujeitos empregados como Papai Noel durante o fim de ano (JSC, 29/11/1998, p.1B; 30/11/1998, p.1B), pois apesar de citar variados espaços do comércio, a foto que ilustra a reportagem é a do Shopping Neumarkt. O que essas fotografias aparentemente aleatórias podem nos indicar? Se Beatriz Sarlo aponta o caráter simulador de urbanidade contido nos shoppings ao nos dizer que "o shopping center, seja qual for sua tipologia arquitetônica, é um simulacro de cidade de serviços em miniatura" (SARLO, 2006, p.14), devido a suas praças, placas indicando lugares e direções em seus corredores largos, muitas vezes chamados de avenidas, veremos que os shoppings começam a pautar a discussão em torno da urbanidade - do que faz uma cidade mais do que mero aglomerado de pessoas, mas algo urbano. Mais do que a simulação ou destruição da urbanidade, os shoppings trazem um novo modelo de cidade.

Dessa forma, podemos compreender como que o uso de uma concepção de tradição ligada à germanidade foi operada pelo shopping, perceptível em seu nome e no amplo uso de decoração com temática germânica durante seus primeiros anos de operação - atualmente esses traços estão apagados. Sua faceta, estabelecida mesmo sendo outsider (ELIAS; SCOTSON, 2000), lhe permitia mais do que legitimidade, lhe permitia dar continuidade à cidade em que foi construído. Mais do que ser da cidade, é uma continuação desta e de sua tradição. A relação entre o shopping e a cidade existe e o que comumente concluímos em esclarecidas abordagens sobre esse tipo de empreendimento é perceber no shopping a negação da cidade, dado o entendimento de cidade e urbano por um viés clássico-moderno, claramente debatido por Jane Jacobs em 
seu exemplo bem acabado do North End, coincidentemente um dos locais mais antigos de Boston.

Mais do que cooperar fortemente para a destruição da cidade de ruas públicas e democráticas, os shoppings indicam uma nova forma de construir cidades dentro do capitalismo. Tratamos de cidades cada vez mais segregadas, constituídas em enclaves fortificados (CALDEIRA, 2000). Sua simulação está na utopia que o capitalismo jamais realiza ao propor e demonstrar um certo tipo de cidade ideal "repleta apenas de cidadãos consumidores, sem vestígios de pobreza e deterioração" (FRUGOLI JR, 1992, p.77). E, dessa forma, inverte-se a afirmação de Sarlo, já que mais do que simular as cidades, com o advento do neoliberalismo e sua ideologia de mercado, os shoppings começam a propor como as cidades devem ser e, dessa forma, a cidade busca simular o shopping. Não por acaso, Mike Davis observa como ao mesmo tempo em que os processos de favelização engrossam, os investimentos privados parecem acompanhar na mesma proporção, seja ofertando crédito, seja através de condomínios fechados (DAVIS, 2006). Essa relação entre o shopping e a cidade não está distante, pois podemos problematizar isso melhor caminhando poucos metros ao observarmos as mudanças e a consequente reurbanização da rua XV de novembro, o grande palco da urbanidade blumenauense.

\section{Retomando as ruas: o processo de gentrificação ${ }^{10}$ da rua $\mathrm{XV}$ de novembro}

Durante a década de 1990, são inaugurados uma série de empreendimentos em contornos de shopping. Apesar de boa parte ter falido, mantinham presença constante nas páginas do Jornal de Santa Catarina. Apresentavam uma proposta de práticas interiorizadas em complexos providos de banheiros, refrigeração e praças de alimentação com generosa oferta de estacionamento. As formas com que esses empreendimentos eram nomeados variam entre outlet, centro comercial, power center e shopping e apareciam para nomear um mesmo estabelecimento. $\mathrm{O}$ grande destaque, o nome de maior prestígio, está na palavra shopping e o grande exemplo é o Neumarkt.

Lidar com entrevistas e provocar uma construção de memória em diferentes sujeitos sobre sua experiência e atuação frente a um processo histórico compreendido como marcante para uma cidade inteira trazem o problema da memória coletiva posto

\footnotetext{
${ }^{10}$ Termo utilizado "para designar intervenções urbanas como empreendimentos que elegem certos espaços da cidade considerados centralidades e os transformam em áreas de investimentos públicos e privados" (LEITE, 2002, p. 112 - grifo do autor).
} 
originalmente por M. Halbwachs (2006). A questão é complexa e apresenta o paradoxo de ao mesmo tempo que cada indivíduo constrói sua própria memória, existem elementos gerais que são compartilhados no imaginário sobre o passado ${ }^{11}$. A distância entre a memória individual e a coletiva pode, metaforicamente, ser medida através do $e u$ e dos outros. Sabemos que há uma relação entre a memória de uma pessoa e sua sociedade, mas como se dá essa relação? A observação realizada por Paul Ricoeur (2007) traz a figura do próximo, colocando a construção da memória entre o eu, os outros e o próximo. Nesse sentido, a construção da memória se dá através da constante fricção verbal dos indivíduos. Na tentativa de dar conta desta dinâmica, as entrevistas foram apresentadas no formato de uma mesa redonda, como se os entrevistados debatessem sobre a construção do shopping Neumarkt e a reurbanização da rua XV de novembro:

Lili: "O shopping Neumarkt ele tem uma marca muito grande na cidade, eu diria o antes e o depois do shopping" ${ }^{, 12}$.

Arno Buerger: "houve uma modificação, [...] principalmente o que ocorreu foi modificação de costume, modificação de hábitos em relação ao blumenauense", 13 .

José Geraldo Pfau: "sempre eram fora da cidade, em Blumenau foi no centro da cidade, no meio da cidade"14.

Irineu Falk: "o shopping aqui do centro eu acho que é o mais bem localizado, o acesso é mais fácil, tem o ônibus, têm o pessoal que mora aqui, têm mais gente concentrada no centro" $"$.

José Geraldo Pfau: "O shopping fez um choque muito grande pela sua proximidade da comunidade se localizando no centro".

Cláudia Siebert: "se esse shopping tivesse ido, digamos, pra região que a gente chama de ZC2, na direção da Antônio da Veiga [mais ao Norte], ele teria levado o desenvolvimento com ele [...] mas ali onde ele foi feito, não havia mais terreno disponível, era morro atrás e um centro consolidado. [...] ele não gerou desenvolvimento no entorno, ao contrário ele matou a rua XV por quase uma década" $"$.

\footnotetext{
${ }^{11}$ Sobre isso há o caso do "bom alemão", figura constante nos mais variados depoimentos de pessoas que viveram experiências traumáticas durante a Segunda Guerra. Para maiores detalhes ver: Alessandro Portelli (1996), "O massacre de Civitella Val di Chiana (Toscana: 29 de junho de 1944): mito, política, luto e senso comum”.

${ }^{12}$ Lili (pseudônimo). Entrevistada por André Procópio Gomes. Blumenau, 20 out. 2015.

${ }^{13}$ Arno Buerger. Entrevistado por André Procópio Gomes. Blumenau, 26 out. 2015.

${ }^{14}$ José Geraldo Pfua. Entrevistado por André Procópio Gomes. Blumenau, 27 out. 2015.

${ }^{15}$ Irineu Falk. Entrevistado por André Procópio Gomes. Blumenau, 27 out. 2015.

${ }^{16}$ Claudia Freitas Siebert. Entrevistada por André Procópio Gomes. Blumenau, 21 out 2015.
} 
Lili: "toda a parte comercial da cidade estava concentrada na rua XV de novembro, desde os primórdios lá no final do século XIX, e com a vinda do shopping Neumarkt houve assim uma debandada eu diria, muito grande das grandes lojas para o shopping Neumarkt".

José Geraldo Pfau: "O shopping surge como uma novidade, é uma nova geração, é uma praça de alimentação, cinema. Tanto que as últimas gotas de sobrevivência antiga de cinema, de lanchonete... tudo se acabou com a chegada deste grande empreendimento que foi o shopping".

Arno Buerger: "com o surgimento do shopping mudou totalmente o mix da rua $\mathrm{XV}$, que antes vendia moda. A moda mais moderna foi pro shopping, porque ninguém leva pro shopping uma loja simples, uma loja muito barata".

Cláudia Siebert: "eu me manifestei contrária, mas até pelo porte do projeto e pelo interesse de muitas pessoas da comunidade, da própria prefeitura, esse projeto foi levado ao conselho de desenvolvimento. [...] o conselho entendeu por maioria, que o projeto deveria ser aprovado, e que portanto o entendimento de que aquilo era um centro comercial era do interesse da cidade".

Arno Buerger: "eu também tinha essa visão que o shopping ia dar certo, como na realidade os shoppings deram certo no Brasil inteiro, tanto que em Blumenau já estamos no terceiro shopping, fora os centros comerciais de sucesso também".

Lili: "será que nossa cidade comporta três shoppings de grande proporção como temos na nossa cidade?".

José Geraldo Pfau: "o shopping fez um papel muito interessante, acredito que o desenvolvimento do nosso shopping não deve deixar a desejar a nenhum tipo de empreendimento, porque não só os empresários locais tiveram suas lojas lá, como também grandes redes".

Lili: "a XV de novembro vai entrando em decadência, e uma decadência tão grande que ela se transformou numa rua quase que de 1,99."

Irineu Falk: "A tendência era dos shoppings aparecerem, foi uma concorrência pras lojas de rua, que as lojas de rua também foram obrigadas a mudar, inclusive fizeram uma reforma geral na rua XV".

José Geraldo Pfau: "a rua XV já tava prejudicada, ela já tinha dado o seu tropeço, ela já estava abalada. Abalada por uma condição econômica, ela já vinha com essa situação de dificuldade".

Arno Buerger: "o shopping no início foi o maior sucesso, e até hoje é um sucesso, é um ponto de encontro e as lojas boas estão lá também. Não tô condenando o shopping não, pelo contrário, eu relevo, aceito muito bem o shopping como um grande gancho comercial pra quem lá está".

Cláudia Siebert: "nas palavras do grande geógrafo Milton Santos, a gente perdeu o espaço do cidadão que era a rua $\mathrm{XV}$, a rua $\mathrm{XV}$ funcionava como uma praça linear, e a gente ganhou o espaço do consumidor".

Arno Buerger: "O principal motivo que levou a revitalização, foi a decadência de Blumenau, em consequência a decadência da rua XV. Quando nós resolvemos revitalizar a rua $\mathrm{XV}$, tinha 33 lojas fechadas, o que é ruim pra todos." 
José Geraldo Pfau: "foi dai que o Arno Buerger [da CDL] junto com o Emílio Schramm que é do sindilojas [...], procuraram o Décio Lima e na reunião que ele oficializou nós estávamos juntos, nós três, fomos a ele para propor uma reestruturação da rua XV. Ai, ele realmente disse: olha isso é um assunto que me interessa bastante. Chamou seus assessores e propôs fazer um estudo e que daria a resposta o mais breve possível."

Arno Buerger: "marcamos um encontro no hotel Plaza em Itapema [...], depois que eu falei pra ele o que eu queria fazer na rua XV, ele bateu na mesa e disse: vai ser a obra do meu governo. [...] todo prefeito quer uma obra consistente, que o povo todo participe e veja".

José Geraldo Pfau: "em resumo, eu acho que a rua XV de novembro reurbanizada modificou completamente o seu perfil, recuperou muito da sua clientela, mas não conseguiu mais voltar o que era, que era realmente um comércio muito forte".

Partindo de François Dosse (2013), a inauguração do Neumarkt em Blumenau foi o grande acontecimento na década de 1990. Por ser o acontecimento colocado como esfinge e fênix, sua volta é constante, sendo um dos poucos "acontecimentos sobre os quais podemos afirmar que terminaram porque estão ainda suscetíveis de novas atuações" (DOSSE, 2013, p. 7), o que se confirma empiricamente nos relatos orais coletados e nas inaugurações mais recentes de dois shoppings centers entendidos muito mais como continuidade do que ruptura em relação ao Neumarkt. Grosso modo, a rua XV de novembro concentrava o melhor do comércio. As melhores lojas se encontravam nela, que concentra ainda muitos escritórios, escolas, repartições, teatro, igreja, praças. Por ser a rua de exposição da cidade, foram construídos em torno dela uma narrativa e significados muito particulares em relação as outras ruas. A XV não é uma rua qualquer da cidade de Blumenau, vide os desfiles que historicamente ocorrem nela. Mesmo durante sua reurbanização, os desfiles de aniversário da cidade e da Oktoberfest continuaram ocorrendo nos trechos transitáveis.

Em 1993, ano de inauguração do Neumarkt, o Jornal de Santa Catarina publica uma reportagem intitulada Lojas da XV se preparam para chegada do shopping, anunciando "ampliar o horário de atendimento ao público" como uma "das primeiras atitudes dos lojistas do centro para acompanhar a nova tendência comercial trazida à cidade com o Shopping Center Neumarkt Blumenau" (JSC, 05/09/1993, p.7; 06/09/1993, p.7). Apesar do tom de alerta, a construção do shopping é vista como "mais uma atração para o município, o que resultará em maior número de turistas", levando alguns lojistas a estudarem "planos e promoções para não perder a clientela" (JSC, 05/09/1993, p.7; 6/09/1993, p.7). A rua XV de novembro, até então o principal nome no assunto comércio em Blumenau, se vê alterada pela construção de um shopping center 
em suas proximidades.

Não podemos ignorar, também, que mais do que um único shopping na cidade, o número de empreendimentos interiorizados nos primeiros anos da década de 1990 era muito grande, seja em sua construção, seja nas promessas anunciadas nas páginas do Jornal de Santa Catarina. Dessa forma, o comércio claramente começava a adotar a pauta do centro comercial, do outlet ou do shopping. O que faria a rua XV?

Uma "remodelação completa" dos espaços centrais "beneficiando-os com equipamentos urbanos para maior conforto do cidadão e do turista, bem como para o embelezamento dessas áreas" (JSC, 28/03/1993, p.9; 29/03/1993, p.9), eram uma saída anunciada. No dia seguinte, o JSC afirma que "o projeto de Renovação e Humanização da Área Central foi bem recebido pelos comerciantes, pela população e por pessoas que trabalharam pela construção da cidade" (JSC, 30/03/1993, p.9). As definições do que fazer na rua XV ainda não estavam claras, o próprio uso de remodelação, reforma e reurbanização aparecem no mesmo texto. Contudo, a necessidade de transformar a rua XV de novembro era algo unânime, havia "uma preocupação dos lojistas com o esvaziamento da mais tradicional rua de comércio da cidade pela proliferação de shoppings e centros comerciais" (JSC, 22/12/1994, p.1A).

Mesmo com um consenso em torno de uma reurbanização da $\mathrm{XV}$, acertos entre a Câmara de Dirigentes Lojistas (CDL) e o Instituto de Pesquisas e Planejamento Urbano (IPPUB) não foram tão imediatos, pois "o maior motivo da discórdia entre CDL e IPPUB é quanto aos locais de estacionamento", sem ignorar o orçamento "estimado hoje pelos lojistas em US\$ 7,5 milhões” (JSC, 12/04/1995, p.3A).

As obras somente iniciaram em 6 de julho de 1999, adotando o regime de mutirão, numa parceria entre "proprietários, prefeitura e Governo do Estado" (JSC, 07/07/1999, p.1B). Isso demonstra que o acerto entre as partes envolvidas no processo de reurbanização da XV não foram tão simples de ocorrer. Antes de mais nada, por se tratar de uma rua e não de um ambiente privado como o shopping, as decisões não poderiam ser centralizadas - ao menos num Estado democrático de direito - e por isso exigiam a típica conversa e negociação que caracterizam a vida pública. O que observamos é "uma combinação de muitos fatores quando uma adesão social se junta à vontade política de retomar o domínio da cidade" orientada pela "recuperação dos espaços públicos" (CATEDRA, 2006, p.186).

O interessante nesse processo de reurbanização está no fato da XV representar a excelência das ruas da cidade de Blumenau. Com isso, podemos entender que ações 
começam a ser tomadas nas outras ruas da cidade. Se o shopping Neumarkt se faz um modelo frente a todos os empreendimentos semelhantes, a XV se faz um modelo para as ruas de Blumenau. Sua reurbanização não foi um evento isolado. Hoje em dia, quem visitar Blumenau, pode perceber que o padrão adotado em toda extensão da XV segue sendo adotado para toda a cidade desde então e nas cidades vizinhas.

Uma forma de analisar a dinâmica urbana das ruas centrais de Blumenau na década de 1990 pode ser realizada numa atenção mais demorada do Biergarten e da Prainha.

A praça Hercílio Luz está localizada no antigo porto de Blumena, devido a um Biergarten instalado lá até 1993, local que ficou assim conhecido até hoje. Esse Biergarten tinha seu funcionamento comum de um Jardim da Cerveja, com mesas espalhadas pela praça e a venda dessa bebida. Porém, em 1993, o local oferecia música para dançar recebendo "diariamente, em época de Oktoberfest, cerca de 6.000 pessoas, tanto turistas quanto moradores da região do Vale do Itajaí". Entretanto, depois "dos incidentes do final de semana no Biergarten, a direção do estabelecimento decidiu promover uma reavaliação da atividade no local” (JSC, 06/11/1993, p.9). Porém, mesmo com as promessas de reformulação do espaço, com direito à nova iluminação vinda de Miami, um presépio eletrônico e uma banda de São Paulo para tocar no coreto, a continuidade de um Biergarten ocupando a praça ocorreu. Em dezembro de 1993 são anunciados pelas páginas do JSC “a concorrência pública e o projeto para melhor aproveitamento do espaço do Biergarten”, o que daria o direito ao vencedor do concurso "explorar o Jardim da Cerveja por um período de seis anos", reforçando a ideia de que o local sirveria "como um espaço permanente cultural destinado para concertos de câmara, promover orquestras e bandinhas nos domingos pela manhã" (JSC, 08/12/1993, p.9).

Em 1995 o caso do Biergarten se prolonga. A ação indicada para o espaço da praça foi abrir licitações com o intuito de "mudar a cara e o coração do Biergarten”, o deixando "sem bailões, mas com as tradicionais bandinhas", também "sem lanches rápidos, mas com quitutes típicos da culinária alemã", ações postas como "um resgate da ideia original do Biergarten” (JSC, 30/03/1995, p.1B). A iniciativa da minicervejaria, construída no local da praça em substituição ao Biergarten (ao ar livre), ficou por conta da Brahma. Sua inauguração em setembro de 1996 contava "com um show de fogos de artifício, apresentação de balé", reabrindo "ao público a Praça Hercílio Luz e [inaugurando] o Museu da Cerveja Brahma” (JSC, 24/09/1996, p.1B). 
Dado isso, a praça ficaria sob iniciativa privada, que explorando o local através de sua mini-cervejaria, manteria o Museu da Cerveja, o parquinho, o jardim da praça e os sanitários.

A Prainha, por sua vez, passa por um processo diferente. Basicamente do outro lado do rio Itajaí-Açu em relação ao Biergarten, seu nome é devido à sedimentação de areia na curva do rio, formando uma prainha que era assim utilizada até meados dos anos 1960. O local se constituía de uma praça pública com espaço para prática de esportes e uma concha acústica para apresentações musicais. Eventos musicais foram uma das formas de utilização do espaço. Contudo, no começo dos anos 1990, ocorria o Skol Rock simultâneo a Oktoberfest. Em meados da década de 1990, o Skol Rock não só cessou de ser realizado na prainha, como em Blumenau. O principal motivo se deu por conta das reclamações dos moradores da região próxima à Prainha. Uma publicação na seção do leitor ilustra esse descontentamento dos moradores da região. Segundo um morador, o trânsito adotava proporções caóticas ao ponto de, sob iniciativa dos guardas de trânsito, ser "impossível manter a disciplina", adicionados os "maus exemplos de pessoas se drogando, palavrões, pessoas urinando em terrenos baldios", somados a queixa de que o parque "todo ano é arrancado, devastado e depois 'reconstruído"” (JSC, 1/11/1996, p.4A).

Após o cancelamento do evento na Prainha, podemos acompanhar pelo jornal que seu espaço entra em decadência. Mesmo que uma das reclamações frente ao Skol Rock fosse por conta de uma descaracterização de sua função original de praça, o descaso e abandono do local foram objeto recorrente nas páginas do JSC a partir de então. Em 1998, é noticiado que a "Prainha sofre com o descaso", havendo algumas pessoas que ainda frequentavam o local "mesmo com os banheiros parcialmente destruídos e o Vapor Blumenau I caindo aos pedaçoo" (JSC, 28/03/1998, p.1B). Apesar da narrativa catastrófica adotada no jornal em relação à Prainha, cabe dizer que havia no local uma pista de skate com um público relativamente expressivo de frequentadores, e nos mais diversos horários do dia. A pista existente no local apresentava um forte caráter de intervenção de seus usuários, contendo muitas vezes a presença de caixotes de madeira e afins trazidos ao local. Curioso que em vez da prefeitura focar nesse uso espontâneo do lugar, foi dada preferência para demolição da pista sob a justificativa de uma nova e melhor pista no Parque Ramiro Ruediger, o que realmente ocorreu após algum tempo. 
Ao longo da década de 1990, temos duas tendências conflitantes se compondo na cidade. Uma seria a do mundo da via expressa descrito por Marshall Berman, claramente representado pela construção de centros interiorizados como os shoppings, centros comerciais e outlets que, apesar de privados, encontram uma ressonância por parte do setor público ao concentrar esforços na construção de vias rápidas, como é o caso da Ponte Tamarindo e os Anéis Viários, até ruas e avenidas principais ganhando sentido único (a exemplo da rua 7 de setembro, avenida Beira Rio e a própria rua XV de novembro), sem esquecer que grandes mercados são construídos nessa região central, a exemplo de dois hipermercados Angeloni. Isso tudo dialoga com uma prática pautada em casas nos limites da cidade, principalmente em razão da especulação menos agressiva nessas regiões limítrofes, uma locomoção prioritariamente automotora e individual, que se conecta às vias rápidas que dão acesso a complexos fechados de consumo. É dessa maneira que o "dinheiro e a energia foram canalizados para as novas autoestradas e para o vasto sistema de parques industriais, shopping centers e cidadesdormitório que as rodovias estavam inaugurando" (BERMAN, 1986, p.300).

Outra tendência da dialética do período está conectada com a experiência passada e sua exigência de cidade com a rua sendo o grande palco da urbanidade e os espaços públicos ao ar livre ocupados pelo cidadão. Se podemos perceber uma euforia com a construção do shopping, também ocorre uma exigência pelo espaço público e a rua, seja no momento de tratar das praças, seja no momento de tratar da XV. Mesmo que pontualidades possam ser colocadas para a cidade de Blumenau, este era um processo geral que ocorria no período. Já se havia consolidado o modelo da via expressa e desde os anos 1970 ele vinha sofrendo críticas. Ao mesmo tempo era/é necessário reconhecer que as cidades cresceram e se desenvolveram de tal forma que planejá-las sem vias de acesso rápido era algo impossível. Esta afirmação é tão clara quanto a dramaticidade urbana que seria curvar-se a esse modelo. Era necessário retomar a cidade e a vida urbana. Mas, como?

Em nenhum momento a rua XV, Biergarten ou Prainha deixaram de ser frequentados. A XV, por ser a rua que atravessa toda a dimensão central de Blumenau, é habitada por um grande número de escritórios - para citar algo além de seu comércio e nunca esvaziou-se. Prova disso foi que, mesmo durante as obras de reurbanização, "em nenhum momento as lojas ficaram sem acesso"17. Mesmo com uma reconhecida

\footnotetext{
${ }^{17}$ Arno Buerger. Entrevistado por André Procópio Gomes. Blumenau, 26 out. 2015.
} 
decadência da rua confirmada nas 33 lojas fechadas anterior a reurbanização, a rua XV não deixou de ter sua importância, não deixou de ser frequentada. $\mathrm{O}$ mesmo pode ser dito em relação ao Biergarten, que conseguia um público considerável aos domingos com seus bailões e cerveja. A Prainha era densamente ocupada durante o Skol Rock e havia uma ocupação regular com direito à organização de campeonatos de esqueitistas e afins. Logo, a decadência relacionada a esses lugares não poderia se pautar pela ausência de público, pois mesmo que uma redução de uso desses lugares possa ser argumentada, eles ainda eram utilizados.

Verdade que os principais elementos apontados na rua XV estavam na presença cada vez mais forte de comércios populares de $\mathrm{R} \$ 1,99$ ou franquias de venda de móveis linha branca e roupas populares, frente um passado habitado por lojas carregadas de maior valor identitário. Por sua vez, o Biergarten encenava relatos de aglomeração exagerada, transbordando a praça e atrapalhando o trânsito, assim como casos de violência física entre frequentadores do local. A Prainha aglutinava várias camadas sociais entre os praticantes de skate que, apesar de sua quantidade de adeptos no Brasil (o esporte mais praticado após o futebol), sempre obtivera um status marginal. Havia, também, um reconhecido consumo de maconha no local, que persistiu mesmo após a destruição da pista. O lugar era entendido como um espaço marginal, perigoso e a ser evitado. Vejamos que independente da construção de uma nova pista, a destruição da então existente demonstra um caráter único de tornar o local impróprio para tal prática. O problema relatado está na forma com que esses espaços são ocupados e não a ausência de ocupantes.

\section{Conclusão: gentrificação ou reurbanização?}

Mais do que uma retomada das ruas, temos um processo de transformação na região central de Blumenau. Vemos a rua XV reurbanizando-se, o Biergarten interiorizando seu uso para uma minicervejaria e a Prainha deixando de receber bandas e não aproveitando o uso do local para a prática do skate. Essa transformação da região central acaba compondo aquilo que se qualificou como processo de gentrificação. Há elementos de gentrificação no processo de reurbanização da rua XV de novembro, mas essa discussão pode se mostrar infértil frente o fato de que as cidades brasileiras observaram esse fenômeno de forma muito menos intensa que na América do Norte ou na Europa. A principal mudança espacial no caso brasileiro está no deslocamento das 
classes médias e alta "em direção aos condomínios fechados" (ANDRADE, 2016, p. $103)$.

O processo na generalização do modelo e a palavra shopping durante a década de 1990, distribuindo enclaves fortificados e, ao fim, produzindo a reurbanização da rua mais simbólica da cidade, nos obrigam a observar algo mais do que um processo de gentrificação. Para além de Blumenau, que cidade de porte médio no Brasil não apresenta seu shopping a céu aberto no final da década de 1990 e princípio de 2000? Há nesse processo a construção de nova forma de observar e entender as cidades.

A reurbanização da rua XV de novembro contou com a articulação de distintas esferas (municipal, estadual e lojistas), uma pauta para fazer a rua XV de novembro continuar a ser a rua XV de novembro, valorizando suas construções e rebatendo na rua as fachadas tombadas pelo IPHAN, revitalizando suas praças, instalando e trocando mobiliário urbano e alargando suas calçadas. As duas figuras centrais nesse processo são Décio Lima com seu governo popular de ações como a gratuidade da passagem de ônibus no primeiro domingo do mês e Arno Buerger, o dono de uma das casas comerciais mais tradicionais da cidade. Observamos mais do que a gentrificação de uma rua, pois temos uma proposta de urbano. Dentre todos os elogios possíveis, teremos este resultado, que não seria nada mais do que um diálogo com o Shopping Neumarkt em relação à cidade ao pautar novas formas de se conceber e se relacionar com o urbano.

$\mathrm{O}$ projeto de reurbanização da rua $\mathrm{XV}$ de novembro ficou cunhado como a tentativa de fazer um shopping a céu aberto. A concepção da rua XV de novembro enquanto um shopping a céu aberto faz parte de uma temporalidade recente, apesar de também aparecer nos anos 1990. No material levantado em torno da rua XV ao longo da década de 1990, tal referência aparece anteriormente aos primeiros passos concretos para a reurbanização. Efetivada a reurbanização, comparações com um shopping a céu aberto escasseiam. Numa reportagem de 1994, menos de um ano após a inauguração do Neumarkt, a rua XV passava por mudanças, em especial a construção de centros comerciais e a transformação de galerias em shopping, dando "uma sacudida na velha rua XV de Novembro", agora "mais do que nunca, um shopping a céu aberto" (JSC, 17/06/1994, Caderno de Economia, p.3). Como justificativa para tal, são apontadas as várias agências bancárias, lanchonetes, restaurantes, farmácias, lotéricas, bares, produtos importados, etc., compondo um mix diversificado.

Quando questionado sobre tornar à XV num shopping a céu aberto, Arno Buerger afirma que "o objetivo nosso era revitalizar a rua $\mathrm{XV}$, sem pensar em shopping 
a céu aberto, $[\ldots]$ ninguém pensava nisso, mas a imprensa destacou esse fato" que, "de qualquer maneira, era um bom chamariz"18. Essa construção narrativa realizada na entrevista, negando a intenção de transformar a XV num shopping a céu aberto, faz sentido ao observarmos a campanha realizada em 1996 pelos comerciantes da rua. Tal campanha de 1996 convidava as pessoas para darem uma volta na rua XV: "é só dar uma volta por lá" (JSC, 06/05/1996, p.5A). Grosso modo, o que essa campanha convida é para o passeio despreocupado e aventureiro pelas ruas do centro, sem resistências às tentações comerciais. A ideia é dar uma volta, afinal a rua é um espaço para se fazer isso. Isso é próprio dela.

Outro evento importante ao longo da década de 1990 fica por conta da realização de um calçadão na rua XV. Além do esperado fechamento da via para circulação de carros, a realização do calçadão normalmente acompanhava atrações variadas. Sua ocorrência não era uniforme, oscilava muito e sem uma periodicidade fixa. Sua intensidade está concentrada nos primeiros anos da década de 1990, para ser retomado em 1998. Cabe observar que entre 1997 e 2004 Blumenau tinha Décio Lima do PT como prefeito. Dentre as políticas adotadas, destaca-se o domingo livre, no qual o primeiro domingo de cada mês tinha a circulação dos ônibus com catraca livre. Diante disso, foi realizado o "Domingo Livre na Rua XV", que rendeu um artigo de opinião redigido por Emílio Schramm, então presidente do Sindilojas. O evento teve boa aprovação, especialmente, entre os revendedores de automóveis, demonstrando ser "um grande gancho para, junto com atrações de lazer e cultura, movimentar o comércio nos feriados e domingos" (JSC, 04/08/1998, p.2B).

Ambas as estratégias, divulgar a XV enquanto elemento urbano e comercial, somada à realização de um calçadão, dialogam com uma valorização da rua enquanto espaço da cidade. Os motivos podem ser os mais diversos, passando pela tradição evocada em torno de uma rua tão significativa para Blumenau, pela resistência de algumas pessoas em se adaptarem ao modo de funcionamento do shopping e, até mesmo, pela busca dos comerciantes por sobrevivência. O que está ocorrendo é um diálogo urbano, um processo dialético em que a existência da cidade não pode mais ignorar a existência de um shopping center. Os acontecimentos dentro desse processo histórico são dois: a inauguração do shopping Neumarkt e a reurbanização da rua XV de novembro. É em torno desses dois acontecimentos que devemos entender os

\footnotetext{
${ }^{18}$ Arno Buerger. Entrevistado por André Procópio Gomes. Blumenau, 26 out. 2015.
} 
significados construídos ao longo desse processo, bem como suas consequências e efeitos.

Em 1998 temos uma breve e intensa polêmica envolvendo o setor comercial: a abertura das lojas aos domingos. "Lei gera polêmica no município" foi a reportagem publicada no caderno de economia do Jornal de Santa Catarina em 17 e 18 de maio de 1998, com direito a duas páginas e alguns entrevistados. Os pontos de debate giram em torno do favorecimento do turismo e da geração de empregos. Os contrapontos estavam no fato de que, durante a década de 1970, Blumenau recebia um número muito maior de turistas sem haver abertura do comércio e os funcionários trabalhariam no regime de rodízio, o que não geraria mais empregos. Dessa forma, a grande pauta colocada fica em torno da "liberdade no horário do comércio em Blumenau" "para atender com mais conforto os clientes, [pois] o comércio precisa trabalhar no melhor horário" (JSC, 19/05/1998, p.4A). Após algumas atribulações envolvendo sindicatos trabalhistas e patronais, bem como o prefeito e câmara de vereadores, a abertura do comércio aos finais de semana vai se estabelecendo de forma legal.

Os primeiros estabelecimentos a abrirem domingo são o shopping Neumarkt e os supermercados, conforme noticiado pelo jornal. É posto que, "com a lei, cerca de 1,2 mil estabelecimentos comerciais no município ganham o direito de abrir aos domingos e feriados sem a necessidade de consultar o Sindicato dos Comerciários", com isso o "Neumarkt deverá agora investir em promoções e, principalmente, na divulgação em mídia no sentido de criar entre o consumidor do município e da região, o hábito de comprar aos domingos" (JSC, 04/06/1998, p.4A). Com esse caso, temos uma síntese do que ocorria, demonstrando as tensões frente às novas mudanças. Basicamente, há uma tendência de que o shopping comece a servir de modelo para a cidade e não mais o contrário. Isto não se dá sem atritos, pois devemos entender que nosso olhar é para o passado, mas as ações analisadas se deram no presente da época. Por isso H. Arendt postula a intensidade do presente localizado entre o passado e o futuro pelo risco eminente da participação em momento tão único que estará relacionado com o depois futuro - tal qual já o está com o antes - passado (ARENDT, 2011). Isso se reflete na abordagem com a rua $\mathrm{XV}$, ora tratada como revitalização, ora como reurbanização, termo que ao final prevalece sem ser menos acertado ao demonstrar seu caráter de nova forma urbana.

A orientação gira em torno do shopping, porém há uma clareza de que o comércio na rua é uma coisa, enquanto no shopping é outra. Vemos isso nos 
depoimentos de Irineu Falk e Arno Buerger, assim como nas campanhas em torno da $\mathrm{XV}$, que demonstram uma certa coesão entre seus comerciantes e sua pauta em desvelar a XV enquanto o que sempre fora, uma importante rua comercial para a cidade de Blumenau. Ao mudar seu perfil, anteriormente associada ao glamour de tempos passados, especialmente por abrigar algumas das melhores lojas do estado de Santa Catarina, para comércios de preços baixos, foi buscada uma reformulação através do exemplo mais bem acabado então presente: o shopping Neumarkt. Percebemos esse movimento mais do que acompanhando a reurbanização em si, mas nas questões carregadas junto com ela, como é o caso de um funcionamento aos domingos.

O exemplo para tal ação vinha da experiência, ao ponto de que em 1996 temos um shopping aberto num dia em que os estabelecimentos do centro (logo na XV, logo nos arredores do shopping) estavam fechados. "Ontem o Neumarkt era a única opção de compras e lazer na cidade", enquanto as "lojas do centro foram fechadas por conta do acordo coletivo de final de ano". "A medida não se aplicou aos funcionários do shopping" (JSC, 21/02/1996, p.8A). Mais do que isso, os números ligados ao movimento e compras eram expressivos.

As grandes mudanças urbanas impulsionadas pelo desenvolvimento do setor terciário têm seu destaque em torno do shopping, "sendo que tais equipamentos tornaram-se grandes centros de convergência da urbes, agindo consideravelmente no modo de vida das cidades, assim como impulsionando o desenvolvimento e transformações urbanas" (SILVA; GONÇALVES, 2012, p. 64). Com isso, os shoppings se assentam como a nova centralidade urbana. A expressão "centro" não implica necessariamente num espaço da cidade que é o centro geográfico, mas algo que expressa a centralidade. Se isso não está mais restrito a um delimitado espaço das cidades, mas a um trato com o urbano, o dos enclaves fortificados bem representados em condomínios e shoppings (mas não só), o resultado é o entendimento do urbano através do shopping e não mais pelas ruas. Dessa forma, os processos de gentrificação estão dialogando com essa nova concepção de urbano, refazendo as cidades, expandindo os shoppings para além de sua construção, mas para as cidades de forma generalizada. 


\section{REFERÊNCIAS}

\section{Fontes primárias}

PREFEITURA MUNICIPAL DE BLUMENAU. Plano diretor físico territorial de Blumenau. Blumenau: Prefeitura Municipal de Blumenau, 1989.

Jornal de Santa Catarina, Florianópolis. 01/01/1991-30/12/1999.

\section{Fontes secundárias}

ANDRADE, Luciana Teixeira de. O espaço metropolitano no Brasil: nova ordem espacial? Caderno CRH, Salvador, v. 29, n. 76, p.101-118, jan./abr. 2016.

ARENDT, Hannah. Entre o passado e o futuro. $7^{\text {a }}$ ed. São Paulo: Perspectiva, 2011.

BERMAN, Marshall. Tudo que é sólido desmancha no ar: a aventura da modernidade. São Paulo: Companhia das Letras, 1986.

CALDEIRA, Teresa Pires do Rio. Cidade de muros: crime segregação e cidadania em São Paulo. São Paulo: editora 34/Edusp, 2000.

CATEDRA, Raffaele; MEMOLI, Maurizio. A reapropriação do patrimônio simbólico do centro histórico de Nápoles. In: BIDOU-ZACHARIASEN, Catherine (Coord.). De volta a cidade: dos processos de gentrificação às políticas de "revitalização" dos centros urbanos. São Paulo: Annablume, 2006.

DAVIS, Mike. Planeta Favela. São Paulo: Boitempo, 2006.

DOSSE, Françoise. Renascimento do acontecimento: um desafio para o historiador entre a Esfinge e a Fênix. São Paulo: Editora Unesp, 2013.

ELIAS, Norbert; SCOTSON, John L. Os estabelecidos e os outsiders: sociologia das relações de poder a partir de uma pequena comunidade. Rio de Janeiro: Jorge Zahar ed., 2000 .

FLORES, Maria Bernadete Ramos (Org.). Oktoberfest: turismo, festa e cultura na estação do chopp. Florianópolis: Letras contemporâneas, 1997.

GOMES, André Procópio. A cidade e o shopping: do mundo da via expressa aos processos de gentrificação em Blumenau-SC (1990-2000). 2016. 192 f. Dissertação (Mestrado em História) - Universidade do Estado de Santa Catarina, programa de Pósgraduação em História, Florianópolis, 2016.

HALBWACHS, Maurice. A memória coletiva. São Paulo: Centauro, 2006.

JACOBS, Jane. Morte e vida de grandes cidades. São Paulo: Martins Fontes, 2000.

KOSELLECK, Reinhart. Estratos do Tempo: estudos sobre história. Rio de Janeiro: Contraponto: PUC-Rio, 2014. 
LEITE, Rogério Proença. Contra-usos e espaço público: notas sobre a construção social dos lugares na Manguetown. Revista Brasileira de Ciências Sociais [online], v. 17, n. 49, p.115-172, jun. 2002.

LUCA, Tânia Regina de. História dos, nos e por meio dos periódicos. In: PINSKY, Carla Bassanezi; BACELLAR, Carlos (Org.). Fontes Históricas. 2aed. São Paulo: contexto, 2006.

PESAVENTO, Sandra Jatahy. O imaginário da cidade: visões literárias do urbano Paris, Rio de Janeiro, Porto Alegre. Porto Alegre: Ed. Universidade/UFRGS, 1999.

PINTAUDI, Silvana Maria; FRÚGOLI JR, Heitor (Org.). Shopping Centers: espaço, cultura e modernidades nas cidades brasileiras. São Paulo: editora da Universidade Estadual Paulista, 1992.

PORTELLI, Alessandro. O massacre de Civitella Val di Chiana (Toscana: 29 de junho de 1944): mito, política, luto e senso comum. In: FERREIRA, Marieta de Moraes; AMADO, Janaina (Org.). Usos \& Abusos da História Oral. Rio de Janeiro: Ed. FGV, 1996. p. 103-130.

RICOEUR, Paul. A memória, a história, o esquecimento. Campinas: Ed. Unicamp, 2007.

SARLO, Beatriz. Cenas da vida pós-moderna: intelectuais, arte e videocultura na Argentina. $4^{\text {a }}$ edição. Rio de Janeiro: Editora UFRJ, 2006.

SIEBERT, Claudia Freitas. Estruturação e desenvolvimento da rede urbana do Vale do Itajaí. Blumenau: Ed. da FURB, 1996.

SILVA, José Borzachiello da; GONÇALVES, Tiago Estevam. Urbanização e produção da cidade: Shoppings Centers na dinâmica de novas centralidades em Fortaleza-CE. Geosul, Florianópolis, v. 27, n. 53, p. 63-88, jan./jun. 2012. 